OPEN ACCESS

Edited by:

Irena Knezevic,

Carleton University, Canada

Reviewed by:

Karly Burch,

University of Otago, New Zealand

Sarah Sippel,

Leipzig University, Germany

${ }^{*}$ Correspondence:

Tammara Soma

tammara_soma@sfu.ca

Specialty section:

This article was submitted to

Science and Environmental

Communication,

a section of the journal

Frontiers in Communication

Received: 21 August 2021 Accepted: 22 November 2021 Published: 17 December 2021

Citation:

Soma T and Nuckchady B (2021)

Communicating the Benefits and Risks of Digital Agriculture Technologies: Perspectives on the Future of Digital Agricultural Education and Training.

Front. Commun. 6:762201. doi: 10.3389/fcomm.2021.762201

\section{Communicating the Benefits and Risks of Digital Agriculture Technologies: Perspectives on the Future of Digital Agricultural Education and Training}

\author{
Tammara Soma * and Bhoosun Nuckchady \\ Simon Fraser University, School of Resource and Environmental Management, Burnaby, BC, Canada
}

British Columbia's food system is experiencing an emerging trend in the digitalization of agriculture, which will impact agricultural practices in the province. The rapid growth of this field has created a niche for training and education in digital agriculture and more specifically, in areas such as robotics, artificial intelligence, big data analytics, and computing. However, it remains unclear whether current educators and trainers in British Columbia are communicating both the benefits and risks of digital agriculture, and the need for an inclusive and equitable approach to digital agriculture. To understand the emerging education and training landscape in digital agricultural technologies, this exploratory study engaged in a key informant interview with 12 participants, including educators, relevant government staff, and private training consultants/practitioners in the food and agricultural sector in British Columbia. The small sample is reflective of the nascent nature of this area of research, which seeks to better understand digital agriculture from the perspectives of agricultural educators and trainers both in the public and private sectors. The study found that there is currently a lack of consideration for equity and food sovereignty in digital agricultural training and education. This is primarily due to a gap in engagement with the social aspects of digital agriculture. Without engaging critical social scientists and critical data studies, digital agriculture education, and training may be conducted in ways that do not promote responsible and ethical innovation, and are therefore counterproductive to the development of a just and sustainable food system.

Keywords: digital agriculture, training, education, policy, communications

\section{INTRODUCTION}

For decades, the agriculture sector in Canada has been undergoing a trend toward a digital agricultural revolution. The promise of digital agricultural technology is that it presents an opportunity for improved productivity and environmental benefits through more efficient use of natural resources (Newell and Taylor, 2018; Rose and Chilvers, 2018). Some of the claimed benefits of digital agriculture are increased yields with fewer inputs, greater environmental stewardship, and social benefits such as less manual labour on farms (Edwards et al., 2020). On the other hand, there are also documented concerns. Weersink (2018) argues that digitization has led to the decrease in numbers of "average-sized farms" in Canada and a subsequent increase in large farms due to 
technological innovations that accelerate production operations. Older farmers and rural farming communities could be excluded from this agricultural digital revolution due to a lack of accessible training and internet connectivity. Farmers might not always understand the data obtained from digital devices and there are also documented issues of trust with respect to data ownership and privacy, as well as a growing digital divide (Rotz et al., 2019; Weersink, 2018; Bronson and Knezevic, 2019). With the development of more advanced technologies such as wireless communication, big-data analytics, cloud-based storage, and data-driven genomes, this data-driven farming requires specific skills and training. The application of digital agricultural technologies and associated training must consider potential harm, farmers' concerns, as well as ensure equity considerations and the sharing of benefits from the technology (Wield et al., 2010; Wiseman et al., 2019).

The Government of Canada has invested around \$49.5 million to engage agricultural stakeholders from the different provinces in the development of digital agricultural tools (Brunner, 2019). For example, one government program - with a $\$ 3$ billion budget (2018-2023) - that aims to increase agricultural outputs using new agricultural technological innovations is the Canadian Agricultural Partnership (Government of Canada, 2020). Such financial incentives provide an immense opportunity for Canadian provinces, including British Columbia, to develop their Agri-tech sector. In July 2019, the Government of British Columbia set up the Food Security Task Force to investigate the benefits and costs of digitizing province's food system (Government of British Columbia, 2020). The findings of the task force identified digital agriculture as the way forward for a sustainable food system which reduces food insecurity and GHG emissions. Some scholars have also argued that such an initiative will lead to an improvement of internet infrastructure to support an increasing range of agricultural activities and countless benefits in rural areas (Bolfe et al., 2020). Another key recommendation by the task force members emphasized the creation of Agri-tech institutions that would facilitate the development of digital agricultural technologies and the training of farmers and students in using these tools (Government of British Columbia, 2020). However, some scholars argue in response to the task force that the focus on technology as a means to achieve food security and sustainable food systems is insufficient and calls for a more cautious approach to the role of agri-tech (Hansen et al., 2020).

It is within this emerging and rapidly changing landscape in both the agricultural sector and agri-food focused institutions that this study will highlight what may currently be a "niche" role of educators and trainers in digital agriculture in British Columbia. Due to what are often polarizing perspectives and communications around the potential risks and benefits of digital agriculture, it is critical to better understand the perspectives of agricultural educators and trainers on how they approach the issue of digital agriculture and identify potential gaps that have not been considered. Moreover, it is important to understand whether or not equity considerations and some of the concerns around the technology are being taken into account in digital agriculture education and training.
With the growing interest in digital agriculture and balancing both the potential benefits and risks around digital agriculture, this study seeks to provide insights into the current trend and the future of digitization within British Columbia's agriculture education/training sector, including in post-secondary institutions, in the public (via government provided resources and training), and in the private sector (via consultants). The study seeks to address the following research objectives: 1) To explore educators'/trainers' perspectives and approaches to the benefits and risks of digital agricultural technologies in their education, communication, and training; 2) To assess whether digital agriculture training and or pedagogy includes/consider outcomes such as social equity and food sovereignty; and 3) To identify appropriate policies to promote an ethical and responsible approach to digital agriculture in education and training. By engaging with 12 educators, trainers, and government staff who are involved in providing agriculture and digital agriculture training in the province of British Columbia, Canada, the findings from this study contribute to efforts to better prepare farmers, educators, and students for emerging trends in digital agriculture. Moreover, a better understanding of educators' perspectives/discourse on digital agriculture can help identify the skills and mindset needed to ensure that learners are exposed to a holistic understanding of both the benefits and the potential limitations of digital agriculture. In this study, a discourse analysis (Paltridge, 2021) will be applied to understand the dominant discourse that is framing digital agriculture training and education, particularly who benefits, and who bears the burden of risk and liability. Discourse analysis can be helpful with respect to understanding how spoken and written words contribute to the construction of certain views of the world (Paltridge, 2021), which in this study is based on how digital agriculture is portrayed by educators and trainers.

\section{LITERATURE REVIEW}

\subsection{Digital Agricultural Revolution: Cause for Celebration or for Concern?}

There has been an increasing call for the sustainable intensification of agriculture to reduce the carbon footprint of agricultural activities, increase food production, and improve the economic conditions of the farming community (Lowder et al., 2016; Firbank et al., 2018). Framing this "fourth agricultural revolution" as "smart agriculture," and "digital agriculture", public discourse and the media have promoted it as the technological fix of future agricultural and food system challenges (Van der Burg et al., 2019). Digital agriculture may take place in the adoption and use of new technologies, the use of advanced sensor capability, improved data connectivity, and computer-based artificial or augmented intelligence (AI) decision support and self-learning systems (Shepherd et al., 2020). While it is a fact that these digital technologies will change the farming culture of communities and agricultural actors, it is still too early to determine how these are perceived 
by stakeholders and assess its impacts on the society (Balafoutis et al., 2020).

Precision agriculture focuses on the data generation process which involves on-the-field collection of data through mobile devices, field sensors and satellites. Digital agriculture, on the other hand, goes many steps further by connecting farm equipment to software platforms (Mehrabi et al., 2021; Clapp and Ruder, 2020). The on-farm data is processed using deep learning algorithms and big stack data to enable the farmers or the company to view all production parameters of real-time operations and provide advice regarding seed choice or application of fertilizer and pesticides (Ozdogan et al., 2017; Clapp and Ruder, 2020). These types of tools and information were once exclusively the domain of agricultural extension services but can technically complement or support extension-related work.

Proponents of digital agriculture argue that the use of technology simplifies the complexity of agricultural activities as more detailed and precise data is available to support complex decision-making on-farm; enabling the move "from precision to decision" (Shepherd et al., 2020, pp. 5083). It is claimed that such precise agricultural data paves the way for farmers to be in line with environmental standards and regulation that are becoming more stringent worldwide (Saunders et al., 2016). Furthermore, on a global scale, scholars argue that these digital technologies will provide greater market access for agricultural products as more information about the farm producing the food will create more transparency and traceability through the use of verifiable records and labelling in complex food supply chains (Shepherd et al., 2020).

Some scholars note that the digitization of agriculture would lead to increased production for fewer inputs and a reduction in toxins from agrochemical use due to more precise chemical applications (Basso and Antle, 2020; Shepherd et al., 2020). This phenomenon, in which more food is produced on less land and with less input, is claimed to result in fewer environmental impacts but also increases farm receipt (Garnett and Godfray, 2012). Greater efficiency and productivity are the main arguments of proponents of digital agriculture as it balances the socio-economic and the environmental aspects of sustainable agriculture and the food system (Basso and Antle, 2020).

However, there are also barriers identified by scholars about digital agriculture. For example, internet access in both urban and rural communities is critical to the uptake of digital agriculture and the use of Big Data analytics platforms (Weersink, 2018). Even in 2021, many rural areas of North America and Europe experience a lack of broadband and internet access because internet service providers do not generate the same profit margin as in large cities where they have millions of customers (Pant and Odame, 2017). Moreover, the average age of farmers in Western countries is viewed as a barrier to digital technology as increasing age has a negative correlation with the adoption of technological tools such as computers and online platforms (Tey and Brindal, 2012).

Beyond barriers to adoption, there are also larger concerns around the use of the technology itself and its potential negative impact on farmers. Often, farmers are captured by sales pitches about a specific precision or digital agricultural system, which can make them believe that acquiring that technology will help them increase crop yield or better manage farm issues. However, the ways in which digital tools are marketed, combined with other powerful social forces, trap many farmers in technological lock-in via debt (McKinnon, 2019). Debt is a key mechanism that farmers engage in to acquire an agricultural technology of a specific brand and system (McMichael, 2013; Rotz et al., 2019). Unfortunately, these agricultural systems are sometimes unable to process agricultural data that come from digital tools of other brands, and this not only reinforces the societal dominance of certain technological systems over others, it also leaves the farmer with financial debt and limited data processing capabilities (Rotz et al., 2019; McKinnon, 2019; McMichael, 2013). Additionally, the dependence of farmers on digital software to guide their farming practices reinforces the technological lock-in as farmers lose their traditional way of evaluating trade-offs and may be unable to fix their machinery or perform agriculture without digital support (Carolan M. S., 2017; Rotz et al., 2019).

While digital agriculture promises environmental sustainability, negative environmental consequences can also happen if the technology is not utilized in the safest way due to a lack of strict regulations. Another major concern is the issue of data ownership. Land grabs in the twenty-first century depend on digital knowledge and needs agricultural data. From a digital agricultural technology provider's standpoint, land represents a block of data and digital agriculture acts as facilitator to capture information about micro-scale qualities of land and lives which are inputted into a data analytics infrastructure operated by multi-national corporations (Fraser, 2019). Such large vertically integrated and multinational enterprises have the data analytic platforms to evaluate the inputted on-farm data (Clapp and Ruder, 2020; Weersink, 2018). Even though farmers agree to the terms and conditions of using digital agriculture platforms, they have little influence in determining consent rights to their data as agricultural companies remain unclear data ownership and whether the data is used for other purposes, such as data sharing agreements with third parties (Custers, 2016; Wiseman et al., 2019). The collection of agricultural data and gene editing by these large agricultural companies make farmers more hesitant to share their data as they fear an agricultural research agenda that will cause economic and environmental consequences (Clapp and Ruder, 2020). Corporate-controlled data analytics platforms are indeed not the most appropriate medium to restore equity among the different agricultural stakeholders and safeguard the privacy and livelihood of small farmers, who feel excluded from the value chain (Weersink, 2018). Sadly, such approach with digital agriculture will continue to widen the profitability gap between marginalized small farmers and multi-national companies.

\subsection{Digitization of Agriculture in Canada}

When it comes to Digital Agriculture, the Federal Government of Canada is actively engaging the different provinces, education and research institutions, large agribusiness companies and small enterprises throughout the country. With a view to becoming a 
global leader in digital technologies for food and agriculture, the federal government has launched the Canadian Agri-Food Automation and Intelligence Network (CAAIN) to regroup 61 technology and agri-food companies including eight core partners such as Alberta Innovates, the Vineland Research and Innovation Centre, Olds College, MDA Systems Ltd., Linamar Corp., Lakeland College, DOT Technology Corporation, and TrustBIX share in the $\$ 49.5$ million contributions from the Strategic Innovation Fund (Brunner, 2019). Additional funding of $\$ 15$ million will be allocated to other small and medium food enterprise partners to be able to work on an automation and digital technology project to highlight the economic benefits and impacts of digitization of the Agri-Food sector (Morin, 2020). Another federal and provincial program which aims to increase agricultural outputs using new agricultural innovations is the Canadian Agricultural Partnership with a $\$ 3$ billion budget (2018-2023) in the agriculture sector. The Canadian Agricultural Partnership is cost-shared between the federal and provincial/territorial governments with the federal government contributing $60 \%$ of the costs of the program and the provincial/ territorial government contributing $40 \%$ (Government of Canada, 2020). This funding is beneficial for start-up, agrifood tech companies involved in a wide range of digital agriculture activities such as farm management platforms, the Internet of Things and novel farming techniques (Schmaltz, 2019).

The Government of Canada is setting the path for the gradual digitization of the agriculture and agri-food sector by providing financial incentives and promoting collaboration between agricultural and technology stakeholders more broadly, as well as in academia. A growing number of start-up agri-food tech companies are also collaborating with the Government of Canada as well as academic institutions (Government of Canada, 2018). The fact that industry (including small and medium-sized enterprises and consultancies), post-secondary institutions, research institutes, and non-profit organizations from multiple sectors across Canada are working with the government in the development of digital agricultural platforms outlines the importance of understanding the nuances of communications particularly around the benefits and limitations of digital agriculture.

\subsection{Agri-Food Systems Education and Training}

In 1870, John Carling, Ontario's Commissioner of Public Works and Agriculture announced that Canada needed agricultural education in "the science of farming" (Lawr, 1972, 334). The growth of nineteenth-century determinism and the intellectual environment that set the precedence of agricultural education is encompassed in the terminology of "scientific agriculture" with a popular expression at that time based on the idea that "the minds of the agricultural should be irradiated with the beams of science" (Lawr, 1972, 335). Early agricultural education at the University of Toronto in the 1850s saw students take courses in Agricultural Chemistry, Comparative Physiology, Mineralogy, Geography, Surveying, Botany, Management of Property, and Farm
Finance (Lawr, 1972). Compared to Canadian agricultural education, the American agricultural education in agricultural colleges flourished with significant public aid and land grants. The Canadian agricultural and education system was very much influenced by the success of agricultural colleges in the United States and the experimental farm model imported from British agricultural training. Reverend Clarke, a representative from Canada and rector of the first agricultural school in Ontario was sent to the United States to study the agricultural school model there. The earliest agricultural school (Ontario School of Agriculture) supported by the government had the hope of not only teaching good farming but also encouraging rural youth to take a farming vocation instead of leaving for the city. In his words, the school should "urge the importance of a higher standard of mental culture and a general uplifting of that noblest and yet most despised of human pursuits, Life on a Farm." (Ontario, 1871, 15 as cited in Lawr, 1972). Some who supported the school noted that "dirty hands" is not a necessary virtue in a farmer (Farmers' Advocate, 1877 as cited in Lawr, 1972).

In the 19th century, the science of genetics, animal and plant nutrition, and animal biology was non-existent or still in its infancy. As such, it took after the first world war for new scientific developments on vaccinations, soil testing, genetics that would support the pursuits of agricultural science (Lawr, 1972). Eventually, a key success of agricultural education and training programs were through the provision of local and extension support in arranging crop competitions, short courses, demonstration plots, and providing direct assistance for farmers. College-trained agricultural graduates of Ontario Agricultural College (OAC) became in demand and their expertise not only filled federal and provincial agriculture departments, their expertise was also exported to other countries (Lawr, 1972). In a nutshell, the history of agricultural training in Canada from 19th to the 20th century primarily focused on supporting vocational agricultural programs for the purpose of extension services and on teaching the economics of agriculture (e.g Agricultural Economics) as well as natural science aspects pertaining to agriculture (e.g plant science, soil science, chemistry, veterinary science, and engineering etc). The science focus was done to avoid the stigma of rural life and dirty work on the farm. The extension principles and methods of agriculture developed in North America and Canada were also transplanted in the global South to promote a particular approach of "scientific agriculture" to food production and agricultural development (Gill, 1996, 3).

However, the social aspects of agriculture, including the impact of agricultural practices on society do not traditionally enter into mainstream agricultural training or courses. In the emphasis on scientific agriculture, there has been a gap in considering the social aspects of agriculture. The social consideration of the impact of agriculture is traditionally housed under social science fields such as food studies, sociology and anthropology, and more recently in food systems. Previously, there were very limited avenues to study food systems as a whole (Hilimire et al., 2014). In recent years, 
however, the number of university programs and food systems related courses increased as agricultural, environmental, and food systems related issues became more prevalent in urban and rural settings (Hilimire et al., 2014; Levkoe et al., 2020). Degrading soil and water qualities, environmental pollution, food insecurity, and accessibility, worsening labour conditions, concerns around food justice, and a changing climate due to industrial agricultural practices began to draw the attention of academia and the civil society in the whole socio-economic and environmental impacts of food systems (Hilimire et al., 2014; Francis et al., 2003). There are growing university and community partnerships around food systems, and an expansion of online food systems-related course offerings (Levkoe et al., 2020). A shift has also occurred in that agri-food system professional, and farmers increasingly need to understand global and local food systems as a whole and recognize the interconnectedness of human and natural systems (Liu et al., 2015). Food literacy education is also shifting beyond nutrition and food preparation skills to increase students' awareness about sustainable food production methods, the need to value the role of farmers, animal welfare, and the socio-economic and political factors shaping the food system (Sumner, 2015).

Within this context, farmers and agri-food professionals will need to develop the skills to deal with the dynamics, complexity, and uncertainty of the different processes in the food value chain (Shulman, 2005; Valley et al., 2018). As the rise of digital agriculture requires professionals who can analyze agricultural on-farm data and operate these new emerging technologies, postsecondary institutions will play an increasingly important role in preparing students, and future agri-food educators, trainers, and farmers for a world where digitization is more pervasive. However, post-secondary institutions are not the only spaces for farmer education and training as farmers may receive agricultural education training from extension services offered by the government, and private consultants. There is also a long history of alternative ways of knowing, sharing, and dissemination of agricultural knowledge both formal and nonformal approaches (Mars and Ball, 2016). For example, community-based extensions support benefits from the social capital of the local communities whether it be "fee-for-service" or free extension support organized by farmers (Yamada et al., 2015).

While historically there has been limited emphasis on food systems education programs that focus on complex food-system issues such as food sustainability, security, quality, and justice, more courses and programs have been established in several North American universities in the past decade (Jordan et al., 2014). Food justice and food equity studies have grown with the increased understanding that developing an agri-food system that is sustainable requires a holistic approach that considers environmental, social, and economic considerations (Migliorini et al., 2020). Equity in the food system also entails consideration of intersectionality and anti-oppression, particularly with respect to race, gender, class, and other factors that may result in inequalities (Sbicca, 2012). Concerns around inequity in the food system are addressed in the various works of social scientists ranging from the lack of justice in migrant labour
(Weiler et al., 2017), to inequities in food access for Indigenous peoples (Skinner et al., 2013) and more. While digital agriculture is covered extensively in natural science and technical science literature, in social science, there is only a scattered and emerging body of work investigating the social aspects of digital agriculture (Klerkx et al., 2019). Carolan (2018) found it surprising that social scientists have only recently started to explore what the Big Data revolution in agriculture will mean for farmers and food futures.

\subsection{Discourse Analysis of Agri-Food Educators and Trainers}

Currently, there is little in the literature to help students or farmers interested in digital agriculture to better understand the nuances (opportunities, risk, and limitations) and the implications of a food system that is highly digitized. As this field is still emerging, agri-food system practitioners, farmers, educators, and students need to start thinking seriously about digital agriculture as it is becoming a major component of the food system and as noted above, there are implications in how digital agriculture may impact everything from land use to food production, data collection, resource management, and more. An understanding of digital agriculture is key to prepare future food system professionals to better deal with its impact, opportunities, and its potential unintended consequences. Discourse analysis is a useful tool in understanding the framing of digital agriculture from the perspectives of educators and trainers that will impart training in this field. The method has been used to understand the perspectives of agricultural extension service workers and improve extension practice accordingly (Fleming and Vanclay, 2009). While the term discourse analysis is used in different ways by scholars in diverse fields (Fairclough, 2003), according to Paltridge (2021), discourse analysis examines patterns of spoken and written language including the relationships between language and the broader social/cultural contexts. It also considers how worldviews and identities are constructed through the use of discourse (Paltridge, 2021). In his approach to discourse analysis, Sinclair (2004) argues that analysis of meaning in discourse should be the key focus. Scholars working in Foucauldian discourse analysis are particularly interested in analyzing power (Cheek, 2004).

Unpacking power and meaning through discourse analysis in the context of digital agriculture is important. The historical context of agricultural education in Canada has sought to break free from the stigma of agriculture as hard labour that is nonscientific and "getting one's hands dirty," to "scientific agriculture" achieved through radiating the brains of "young men" with "the beams of science" (Lawr, 1972, 335). As such, understanding communication around digital agriculture is particularly important. Digital agriculture in its form seems to be the pinnacle of rational scientific agriculture that takes the literal "dirt" out of the business of farming. When data analysis from digital agriculture is seen as neutral, transparent, efficient, and rational, it takes away from the human dimension of agriculture and the human/corporate values behind data algorithm. Bronson et al. (2021) has identified the potential 
human impact of data bias in digital agriculture, thus perforating the notion of analysis of agricultural data sets via digital agriculture as unbiased and simply telling "the truth". As it pertains to telling the truth, Miles (2019) cautioned that despite the framing of digital agriculture as revolutionary in promoting sustainability and solving global problem of hunger, the proponent of the technology seems to be rooted in the same values of intensification and the structures of capitalist organization of production that offer little in terms of equitable transformation. Discourse analysis can help unpack these structures through the analysis of educators and trainers' perspectives.

\section{METHODOLOGY}

\subsection{Case Study: British Columbia}

Most of British Columbia's fertile soils are found in sinuous river valleys such as the Fraser River Valley, deltas, and the plains of the northeast. As per the Canadian Land Inventory, only $5 \%$ of the province 92,250,929-hectare land area is suitable for agriculture, $2.7 \%$ is capable of growing a reasonable range of crops and $1.1 \%$ is prime agricultural land (Smith, 2012). B.C. producers led the nation in farm sales of blueberries, sweet berries, prunes, raspberries, apricots, and pears while ranking second in farm sales of floriculture products, mushrooms, and watermelons and apples (AgriService B.C., 2019). The decreasing national trend in the number of farms and an increasing average of farm operators are also reflected in the agricultural landscape of British Columbia (Statistics Canada, 2021). A rise in the adoption of precision and digital agriculture tools has also been observed among British Columbia's farming population to modernize and boost farming operations while the number of people employed in the province's agriculture and agri-food sector is on the decline (Statistics Canada, 2021).

British Columbia remains the most diverse agricultural province in Canada since it produces over 300 agricultural products ranging from fruits and vegetables, dairy, livestock, poultry, eggs, fish, and seafood (B.C. Food Security Task Force, 2020). In 2016, around 50\% of farms were using computers for farm management purposes and 1,432 out of 17,528 farms, which represents around $8 \%$ of all farms make use of Geospatial technology such as GPS technology and GIS Mapping (AgriService B.C., 2019). When it comes to automation technology, $12.8 \%$ of the farms in the province have already started using automation technology and the most common ones being automated animal feeding and automated environmental controls for animal housing (AgriService B.C., 2019). All these facts highlight the trend of digitization in the province's agricultural sector, and an equitable outcome in the realm of digital agriculture will require coordination among the provincial agricultural industry, academia, government, and other food and farming stakeholders.

\subsection{Research Design}

Digital agriculture education and training occurs in many different places including in classrooms, in the field and through online resources. As such, to evaluate educators'/ trainers' perspectives, strategies, and approaches to digital agricultural technologies in their education, communication, and training; and to assess whether digital agriculture training and or pedagogy includes/consider outcomes such as social equity and food sovereignty, we identified a broad range of relevant groups who offer educational or training services around digital agriculture. The first group of key informants are individuals from universities/post-secondary institutions with an agriculture/ food system focused department (“Academic"). We specifically excluded nutrition/dietetics focused programs. A preliminary internet research found that only 8 out of 25 post-secondary schools (public universities and colleges) have an agriculture or food department in British Columbia. This represents a percentage of $32 \%$ of universities and post-secondary colleges addressing food and agriculture issues of the province. Postsecondary institutions that tackle agricultural issues in British Columbia include the Faculty of Land and Food Systems at the University of British Columbia, the Institute for Sustainable Food Systems at Kwantlen Polytechnic University, British Columbia Institute of Technology, Simon Fraser University, and the Food and Agriculture Institute at the Fraser Valley Institute. The second category of key informants are private consultants and agricultural trainers ("Consultants") who specialize in training farmers/agri-food system professionals on agriculture more broadly, and digital agriculture specifically. Farmers may pay to attend their workshop, or the trainers/consultants may go directly into the field to conduct private training. Private trainers may provide practical hands-on lessons on digital agriculture, including but not limited to, how to use drones and applications. The third category of key informants are public sector workers ("Government") who provide educational resources, extension related work and training on a broad range of digital agriculture, including open access resources and online information. They may conduct outreach activities to promote digital agriculture resources, or farmers who are already familiar with their services may reach out to them.

This research project was conducted amidst the first wave of the COVID-19 pandemic (July 2020 to November 2020) and all in-person research activities had been suspended by [Name of University's] Research Ethics Board (REB). To meet the objectives of this study, a qualitative research method was adopted which would not require in-person research activity. While 31 relevant individuals were identified and initially contacted for a semi-structured key informant interview, due to COVID-19, many of the potential interviewees, particularly post-secondary educators noted challenges around scheduling, as such, the final tally of key informants included a total of 12 participants from academia $(n=4)$, government staff $(n=4)$, and private trainers/consultants $(n=4)$. The educational background of the educators and trainers vary, with all the participants, except for one, holding graduate degrees (Masters and Doctoral degrees). Five of the participants interviewed had doctoral degrees. Some of the participants hold interdisciplinary degrees covering both the natural and social sciences. Educational backgrounds include but are not limited to, soil science, agrology, Geographic Information Systems, pest 
management, sociology, resource and environmental management, environmental studies, agricultural education, horticulture, agroecology, ecology, biology, mathematics, and physics. Compared to the natural science/hard science, there were fewer social scientists trained educators interviewed (e.g. sociology, environmental studies). Due to the small number of educators and practitioners knowledgeable about digital agriculture in British Columbia, we have avoided connecting the quotes with the participants' academic training or listing detailed information about the educational background of the interviewees as this might identify the participants in our study.

A gift card of \$ 25 was offered to all interviewees as a token of appreciation and several declined. The interviews lasted between 25 and $55 \mathrm{~min}$. Although all the interviewees are experts in teaching and training on food and agriculture, some interviewees had only cursory knowledge of digital agriculture, which we will discuss further in the findings.

All the interviews were conducted by phone or Zoom and then transcribed verbatim. The contents of the interviews have been anonymized and interviewees are identified by sector (e.g academic, government, and consultants). NVivo Data Analysis Software was used to analyze the codes from the interviews. The interview transcripts were uploaded, and a thematic coding approach was used to code the interviews by assigning a "node" for each main theme related to each interview question. The interview transcripts and the responses to each interview question were reviewed to highlight important quotes and emerging ideas from the answer and assign them to its specific main theme node.

In applying discourse analysis (Paltridge, 2021), the statements were analyzed to better understand participants' perspectives around digital agriculture, particularly as it pertains to educators'/trainers' perspectives of the benefits and risks; to assess issues of equity and food sovereignty; and to identify appropriate policies to promote and ethical and responsible approach to digital agriculture education and training. The findings from the study are categorized into key themes based on the NVivo coding. In this paper, we will focus on how the participants approach the topic of digital agriculture in their role as academics, consultants, and as government staff who provide resources on the field. Their approach, perspectives, and communications as it relates to the topic of digital agriculture informs and will shape future generations of agri-food professionals.

\subsection{Limitations}

The study was conducted during the first wave of the COVID-19 pandemic and since there was a ban on social gatherings, the recruitment of potential participants via emails was not as fruitful. This was particularly the case for the academic participants in the study as the COVID pandemic increased the workload of many post-secondary educators. One aspect to note is that since there are not very many educators and trainers working in this field, those who work in this field are expected to know the newest agricultural trends, technologies, and various aspects of digital agriculture.

\subsection{Findings}

In the following section, we have structured the findings based on the three research questions posed in this study. Although the findings are categorized based on the three overarching research questions, there were overlaps in some of the themes.

\subsection{Educators' and Trainers' Perspectives on the Benefits and Risks of Digital Agricultural Technology \\ 3.5.1 Varying Definitions of Digital Agriculture}

Prior to identifying the benefits and risks of digital agriculture from the perspectives of the interviewees, it is important to first identify the educators' and trainers' perspectives on what is meant by digital agriculture. Considering that the individuals we interviewed came from diverse disciplines and fulfilled diverse roles, setting the baseline on definition is useful.

Digital agriculture is an interdisciplinary field which involves agriculture, mathematics, engineering, computing science, and more. While the professors and experts interviewed are agri-food experts, it was very difficult to find someone knowledgeable in all of the aspects of digital agriculture. Despite the Canadian governments and the private sector investing millions of Canadian dollars in the agri-tech industry, digital agriculture is a relatively new concept, and most of the universities are not currently focusing on this topic. Those that do cover the issue in general still have a cursory or very specific knowledge for a particular technology.

As noted in the literature, there are multiple definitions of digital agriculture (Shen et al., 2010; Kooistra et al., 2015; Ozdogan et al., 2017). The first question asked to the participants was how they would define digital agriculture. Out of the twelve interviewees, eleven participants gave general and neutral comments about how agriculture and technology are currently more intertwined due to the increased use of computers, sensors, drones, cellphones, and decision support systems which contribute to gathering and analyzing on-farm information by farmers. Six participants elaborated on the relationship between data collection and the use of algorithms and big data to analyze on-farm data. On the other hand, another five participants defined digital agriculture as the same as precision agriculture. While some precision agriculture can indeed be part of the suite of digital agriculture, digital agriculture is much broader. This finding has implications for learners as it shows that some of the participants are conflating precision agriculture with digital agriculture, when precision agriculture is mostly concerned with using tools and equipment to collect granular on-farm data so that farmers can monitor farming activities. Digital agriculture on the other hand also covers advanced analysis on digital platforms to create value out of the data. Duncan, Abdulai and Fraser (2021) use the term "digital agriculture" to cover any form of information and communication technologies used in the field to make automated or non-automated decisions and practices. The conflation of digital agriculture with precision agriculture has implications as learners might not be exposed to the broad scope and diverse range of digital agriculture and applications. Although eleven of the participants defined and communicated digital agriculture in more neutral terms, one academic had negative views about digital agriculture and defined it as the following: 


\begin{abstract}
High technology, high-cost, and technologically dependent agriculture that only those with the most money can benefit. Although I know technology is part of our sustainable future, what immediately comes to my mind [when thinking about digital agriculture] is an unsustainable future. (Academic 1)
\end{abstract}

This statement demonstrates that within the realm of food and agricultural training, digital agriculture is a loaded term. As noted by the interviewee above, they felt that "only those with the most money can benefit" from digital agriculture (Academic 1). It is important to note that due to the broad nature of digital agriculture, digital agricultural tools can in fact include lowcost mobile technologies or free apps, and may not necessarily be as costly as other digital agriculture tools such as automated artificial intelligence controlled smart farming systems (Duncan et al., 2021). As such, it is clear there are gaps in understanding the diversity of digital agriculture tools available (both low cost and high cost), and the types of practices and technologies included are not necessarily agreed upon.

\subsubsection{Benefits of Digital Agriculture}

Concerns and opportunities have been identified around digital agriculture as noted in the literature (Rose and Chilvers, 2018; Weersink, 2018; Rotz et al., 2019; Edwards et al., 2020). As the participants interviewed are involved in the training of future students and farmers, it is important to understand the discourse around the benefits of digital agriculture. In this section, beyond the direct benefits of the technology as stated by some of the educators and trainers, they also noted the benefits of employment and training opportunities. We therefore identified the types of digital agriculture training and education currently offered by the trainers and educators. In general, there was a wide range of responses concerning the benefits of digital agriculture use; the main ones being the potential emergence of open-source data platforms, more precise agricultural practices, and the labour-saving aspect of farming. Five participants identified open-access platforms and open-access data as an important benefit of digitizing the agricultural sector and as an opportunity to equitably distribute the benefits of digital agriculture. Two educators stated that digital agriculture would act as an equalizer in terms of information access. One stated that "there is this whole world of open access/open-source technology and communities surrounding these that can promote equity" (Academic 2). The promise that digital agriculture could lead to more precise agricultural practices was shared by five participants. One educator explained how such a benefit would happen:

Digital Agriculture presents the possibility of... instead of reducing the complexity, we take all the complexity, and we learn from that. But to do that, we need to have a large enough data set. So, the only way to deal with complexity and all these interacting components is to have enough data. Hence, Digital Agriculture provides the opportunity to have these large data sets to analyze the complexity so that we pull out some lessons to enable us to more precisely manage agriculture. (Academic 3 )

Another private trainer emphasized the potential to improve resource use by making agricultural practices more precise and targeted. As one consultant noted, "digital agriculture would allow for more efficient use of resources. Whether it is water and fertilizer, it would be used in a more precise way." (Consultant 1). As identified by most of the interviewees, making agricultural practices more precise can be achieved by gathering large sets of on-farm data and analyzing these data sets so that a farmer knows how much agricultural inputs to put in different sites of the farms. While this may be more relevant in the context of large, monoculture farms, the idea promoted is that with more data, better information can be obtained and therefore help influence farmers' decisions in terms of yield, production, income, and energy use. With regards to opportunities, digital agriculture has been framed as an evidence-based and scientific approach to promote better resource and environmental management. Moreover, when mobilized in the form of open access data, one participant noted that "it [referring to digital agriculture] could be a great equalizer" (Academic 3).

Out of the four academics, three were involved in assisting students with digital agriculture projects. These projects were more about using digital software to analyze research data on agriculture. One professor explained:

\section{I require everyone to complete a research project which includes a statistical analysis and students must take a statistics course as a prerequisite for the research project. I also teach experimental design and analysis and we use $R$-based analysis techniques. Honestly, there are some students that are excited about the open-source and open-access capacity of $R$ as an easily powerful modifiable tool while some students are absolutely intimidated by it. (Academic 2)}

Several professors also work in developing open access apps and work with open access digital software (Academic 4) to train data scientists. Machine learning and big data analysis are the focus of digital agriculture training at the tertiary level. Much emphasis is put on the statistical analysis of environmental data to enhance the technical skills of students for the world of work. This is explained by one professor:

I purchased a drone to be able to use in my undergraduate courses. The machine learning that we use in our lab is a combination of regression analysis ... So, they need to be literate in the concepts and our graduate students need to have the skills because this is what is cutting edge. It is a place where you could create a niche where students are able to engage with agricultural systems or agricultural management that they otherwise would not. I would say around twenty percent of the students who contacted me would be interested in digital agriculture. (Academic 3) 
Three government officials elaborated on the different webbased free open access digital tools such as the soil nutrient calculator that the Ministry has developed to help farmers adhere to regulations and improve their farming practices. One government official who has been involved in the development of digital platforms for agriculture stated that a significant amount of funds for training has been invested in digital agriculture training and education including on how it can assist with issues of climate change:

One example of regional support, we provide a lot of money to an organization called the Climate Action Initiative and where possible they develop educational and training tools. They help educate farmers on how a changing climate will impact farming and sharing tools and resources that will help them adapt. So, for example, they will often go out and go to a workshop in a region on irrigating in a changing climate and that story will also be promoting the water calculator and soil nutrient management tools. (Government 2)

Another government official identified student cooperatives (paid internships) as important training programs for digital agriculture. He noted that co-op students from universities are also hired and work on agricultural projects, therefore providing practical employment opportunities. While students gain basic technical skills during work on school projects, a co-op placement in the provincial government or even private sector helps them to apply their technical know-how and get the experience of working in their field. Two of the private consultants interviewed were directly involved in assisting farmers with digital agriculture. One of them stated:

We have also been involved in some work with drones and infra-red to get better information about soil mapping and the field to help farmers to plan, how they fertilize and how they manage crop nutrition based on the information of different types of fields/ soil type. We were also involved in work using sonar technology related to field drainage (different sorts of soil drainage of the field). (Consultant 1)

The method of education and training used by consultants, government staff and professors included both online and inperson training, in classroom and at the farms.

\subsection{3 "Move With Caution" Risks of Digital Agriculture Technologies}

In identifying potential risks and harms, the participants identified concerns around data ownership by large corporations, potential use of data for harmful purposes, negative unintended consequences, natural resource exploitation, increasing debt, and surveillance by government. To sum up the findings, there was an overall theme of "move on with caution." There were various expressions of concern amongst the participants on the potential harm of digital agriculture. Many of these concerns raised by educators and trainers were concerns relayed from farmers or students that they work with or from secondary research. During the interviews, seven out of the twelve interviewees identified data ownership as the main concern of farmers and users of digital agriculture. The control and use of farmers' data by multi-national companies is an ongoing practice, particularly as more digital platforms are offering solutions and analyses to farming challenges. One professor expressed that the older generation of farmers which constitutes the majority of the farming community faces difficulty in understanding what is happening to their data and where it is kept. Surprisingly, the participant (Academic 4) also identified that farmers are not only afraid of their data being used by multinational companies, but they are also concerned about data being used by the government. When one government official whose task includes providing resources on digital agriculture was asked about whether there is trust in governmental institutions around digital agriculture and data, she explained the issue has to do with the fear of potential surveillance:

There are concerns about government oversight and regulatory issues that farmers face... If you are a very small farmer and not making a lot of money, you may not be fully paying all of the required taxes. There may be some loopholes that people are using, and they are concerned if we have their information and premises identification, we will be giving these to the CRA or even water licensing people. There is a lot of concerns over sending information into the government "Blackbox." We see a lot of things such as we send them an email and on the same day, they get an email from other ministries such as water licensing, they automatically assume that we have been giving that information. (Government 1)

Agricultural data plays a major role in the proper functioning of farms and if farmers are the sole proprietor of their data (which ties to the second research question on food sovereignty), they recognize the strength and weaknesses of their own activities. If other external forces such as the government and multi-national companies are at the receiving end of such digital platforms and data, farmers are concerned that their weaknesses and strengths will be shared in the public domain. In a nutshell, digital agriculture may be viewed more of a liability than a benefit for them.

The next risk identified is the potential exploitation of resources. As one academic noted, while there is enthusiasm and excitement in incorporating digital technology into agriculture, it is important to move with caution, particularly as it pertains to unintended consequences around the potential elimination of ecosystem services:

...there is a lot of enthusiasm and excitement related to ways we can incorporate digital technology into our framing system. I think digital agriculture is wanted but we need to move with caution. There are some movements towards highly technical farming which could end using far more resources because these 
eliminate ecosystem services when we try to replace ecosystem services with technologies. (Academic 2)

In addition to potential environmental impacts, another challenge identified as a key theme is economic risk, particularly debt. Three of the participants believed that investing in digital agriculture would result in an increasing debt load for small-scale farms. One of the academics interviewed is particularly concerned by the livelihood of small-scale farmers and advanced that farmers should think carefully before investing in new technologies as their return on investment may not always be economically viable. $\mathrm{He}$ explained:

Technology is invested and wasted. We have these supply managed commodities here in BC. The dairy industry is one of them and dairy people have the most debts of any of the farmers and yet they are guaranteed income. Their debt is all about technology because they keep innovating. This is the concept of the technological treadmill. What it has done to farming and the economics of farming. You adopt these technologies to increase your production (early adopters), and everybody adopts it and then it becomes a fixed cost to production. Everybody is producing more and therefore the value of production is less ... And you are left holding the bag and therefore farms are going broke left and right. (Academic 1)

As identified in the literature review, many farmers are faced with being "locked-in" to certain agricultural technologies (McKinnon, 2019; Rotz et al., 2019). Farmers tend to acquire these genetically modified seeds or agricultural technologies by engaging in debt. This concern is echoed by one private training consultant who believes that financial literacy is key and communicating the need for farmers to thoroughly assess their digital agriculture investments is critical to avoid further debt. He explained:

You got to bring the financial equation in and do a study... how much they are paying in debts per year $v$ s the increased returns compared to that debt, compared to the interest rate at the time. Right now, the interest rate is very low (down to 0\%) and farmers might think that it is a good time to get into the market for buying equipment and they gamble on the fact that the world economy will recover in three to four years. In this case, the interest rate will go up to 5\% and they will be hooked. I think this question needs to be asked parallel to the financial dimension of the investment of all that equipment. Anyone teaching farmers about these kinds of stuffs should be ready to open the spreadsheet and be honest around the numbers (Consultant 2)

In identifying the need for financial literacy, there is an emphasis on farmers' personal responsibility or the educators' responsibility to assess the economic merit of digital agriculture. However, the sheer amount of information on digital agriculture, the technical jargon, complex software and algorithms may make it difficult for farmers to fully recognize the economic and legal risks, as well as benefits of adopting a particular digital agriculture tool.

\subsection{Social Equity and Food Sovereignty: A Missing Link in Digital Agriculture?}

Equity concerns around digital agriculture were primarily framed on the lack of access to the technology, barriers to the adoption of the technology, and barriers to benefitting from the technology. Despite several participants expressing concerns regarding equity issues and advising to move forward with caution, few focused on integrating equity considerations as part of their training on digital agriculture. Most participants were focused on the practical usage of the tools and data analysis. If equity was included, it was mostly to consider how to create more access or developing apps that ensured farmers had ownership of their own data. For government staff, the notion of digital agriculture as "the great equalizer" can be mobilized by open-access digital agricultural platforms and offering cost-shared programs for farmers to make the technology more affordable and accessible. The question of whether or not digital agriculture will be able to transform an inequitable system, and whether or not there is a role for the perspective of critical social science is currently missing in most of the perspectives of educators and trainers (with a few exceptions). With respect to inequities in the food system, particularly between smaller farmers and larger operations, one consultant expressed concerns that digital agriculture adoption could alter the food system landscape in rural areas and many family-owned farms would be financially affected if they do not sell out to big companies:

Digital agriculture is adopted more easily by larger operation farms and more commercialized farms and is less likely to happen on family-owned farms. In the context of generational change, it will continue and there will be a trend towards larger corporation and more digitally integrated and it will lead to a reduction in the number of family-run operations that will have an impact on the agricultural landscape in the [Name of region] ...Family-owned farms will be selling out/leasing their lands to big operations. (Consultant 3)

With respect to smaller farmers being squeezed, one government official had a more positive outlook on how digital agriculture could help with social equity. The main argument was that technological innovations continue to happen in all sectors and digital agriculture is useful for reducing farmers' workload:

The technology side could attract more farmers to some extent. Because farming was thought of initially as weeding and feeding and technology changes how it [agriculture] is being done. It is appealing and could be attracting more people than it would in the past. (Government 2)

The labour argument has been identified in the literature with automation potentially reducing the need for labour and labour 
cost (Rotz et al., 2019). However, there may be negative unintended consequences to reducing farm employment and making farm labour disposable, especially since the agricultural sector employs many people.

In addition to equity, the study is interested in understanding whether digital agriculture training and pedagogy includes considerations for food sovereignty. Food sovereignty is another key ingredient in the development of a just and sustainable food system. Food sovereignty is defined as "the right of local peoples to control their own food systems, including markets, ecological resources, food cultures, and production modes" (Wittman, 2011, 87). Themes around food sovereignty issues were limited and arose with regard to three issues: surveillance and data ownership, concerns around land grabs, and the loss of tangible agricultural knowledge due to a dependence on technology to make the decision. With respect to data ownership and data use, one professor commented on how multi-national companies have misused agricultural data from small farmers to grab their fertile agricultural land:

There are several studies on land grabbing that has access to information about land productivity potential, that has become more available to multi-national corporations... There are bundles of studies coming out about data colonialism. (Academic 4)

Despite using the term "data colonialism" in the context of land grabbing, there was no mention of Indigenous issues around digital agriculture or land access in any of the interviews. This is a major gap considering that agriculture in the province is largely practiced on unceded Indigenous territories. In not recognizing the importance of traditional ecological knowledge and Indigenous land, digital agriculture may be taught in a way that is antithetical to Indigenous food sovereignty. Another aspect of food sovereignty highlighted by one educator is concern around the potential loss of tangible knowledge. One professor raised a concern that farmers who adopt digital agriculture could be too reliant on digital data and would lose the ability to make decisions based on their observations and experiences:

If we build agriculture in an engineering system, rather than a biological system, we lose this connection to what is intuitive on the land. I guarantee you that the people who are good at digital agriculture and analyze these big datasets are not the people who will make decisions on the ground to keep plants and animals alive. (Academic 3)

The argument is that farmers should have the necessary tacit farming skills to ensure resiliency in the event of technological breakdown (Carolan M. S., 2017).

\subsection{Policies for Ethical and Responsible Education and Training in Digital Agriculture Innovations}

To better support responsible and ethical education, training, and innovation in digital agriculture, it is important to address the many barriers to access and adoption. Many of the participants argue that the infrastructure and resources to employ digital agriculture is not sufficient in the province. There are currently numerous barriers to the access of digital agriculture in the farming community, which limit who may benefit from the technology. However, there were interesting responses arguing that digital agriculture is diametrically opposed, and therefore cannot be reconciled with regenerative forms of agriculture. The table below (Table 1) shows the frequency of the barriers to digital agriculture adoption identified by the twelve participants.

The issue of "digital divide" around internet access was mentioned by seven participants as both an equity issue and a barrier to adoption that needs to be addressed by policymakers. Many rural parts of British Columbia are still excluded from internet access because internet service providers are not investing in the infrastructure due to smaller populations and more physical constraints. One professor stated that before focusing on digital agriculture, this gap needs to be addressed and is a role that the government should support:

The places where most marginalized framers are the places with the worst internet access. You can have all the digital technologies in the world but if people cannot afford a data plan, they are left out. (Academic 4)

Five participants mentioned that a lack of training and education deters many farmers from adopting digital agriculture since they are unsure of how to use digital agriculture devices. This is largely due to digital agriculture being developed without necessarily engaging and considering farmers' ability to use or understand the technology. As noted in the previous section on training in academic institutions, at the back end, digital agriculture applies extensive statistical analysis, regression, computer science, and modeling. In a way, it may further divide farmers. When trying to fix digital agriculture based farm tools, farmers are faced with "digital locks" on technologies or proprietary software, which means that farmers ability to fix is limited (Carolan M., 2017). One private consultant (Consultant 3) expressed that digital agriculture would be more viable if farmers have a support system "where there is a full-time technician who responds to the technical issues faced by producers." These types of support require stronger investment in extension support, which is currently limited in British Columbia.

What is perhaps interesting is the view of three participants that regenerative organic farming is incompatible with digital agriculture. This perspective emphasizes the polarization of this technology despite digital agriculture comprising a broad spectrum of technologies and analytical tools that can be utilized by regenerative and organic farms. There is a lack of current engagement between digital agriculture proponents and developers with regenerative agroecological farmers/groups. Some of the more complex, automated, "intelligent" technologies are also developed for larger monocultural farms and are not conducive to more diverse landscapes. One academic was quick to note that some of the digital tools used in digital agriculture is not new at all: 
TABLE 1 | Frequency of the different barriers mentioned by the 12 participants.

Debt

Not enough training and education

Lack of support system to help respond to technical issues (e.g extension support)

Older farmers hesitant to adopt new technologies

The adoption of other types of organic regenerative farming

COVID-19 Pandemic

7

5

5

4

3

3 when I think about databases for example, they quickly supplanted paper records, spreadsheets became very useful, GIS systems for farms- have been used since the 1990s-these are digital technologies and applications. As digital technologies improve, there is a greater opportunity to apply new capacity to farm (Academic 2)

He continued to explain that digital agriculture depends on who owns the technology, how the technology is designed, how the information is used, and for what purpose. This is where digital agriculture can either be used ethically and responsibly, or used to promote harmful practices.

In terms of the future of farming and digital agriculture, access to agricultural land remains the main obstacle for people to be involved in agriculture (White, 2012), but it has been argued that digital agriculture represents an opportunity to attract young people to the field by providing them with highly specialized skills to understand best practices in an increasingly digitized agricultural sector (Panday, 2017). While proponents of Digital Agriculture (Balafoutis et al., 2020; Basso and Antle, 2020; Shepherd et al., 2020) always refer to digital agriculture as the future of agriculture, it was very insightful to hear what the participants had to say about youth and digital agriculture. Nine out of twelve interviewees affirmed that digital technology is not the critical factor that draws young people to the field of agriculture. One consultant stated:

Digital agriculture makes it easier for young people to understand what they are doing and how their actions influence their outcome. If young people are not interested in agriculture, Digital agriculture would still not make them want to farm. Young people who want to operate these self-driving tractors but who are not interested in grain farming will be less likely to get involved in agriculture (Consultant 3 ).

Another academic noted that despite teaching digital agriculture, two-thirds of his students would rather not have to worry about the technology (Academic 2). Three participants including one professor and two consultants pointed out that most young people who want to become farmers do not have the capital investment to acquire land, nor can they afford digital farming equipment such as self-driven tractors, computers, and drones. Moreover, they argue that those young farmers are focused on community-scale farming and will only adopt a specific technology if it aligns with their vision of a sustainable food system. One professor explained:

This new generation of farmers want a very different life. They are not very hyper capitalistic. They do not see themselves first and foremost as businesspeople like other modern agriculturalists. They feel connected to the land, to plants and animals and to the process of producing wholesome food or the community they feel connected to. They will embrace technology that will help them to achieve this goal and not antithetical to that. This is what I think (Academic 1).

The perspective above speaks to a clash of values between what has been framed as a hyper capitalistic approach (i.e digital agriculture proponents) versus a new generation of farmers that have different lifestyles and worldview(s) with respect to farming. Technology will be embraced if it can help farmers achieve the wholesome food system that they would like to see. As the professor noted, the idea of "wholesome" is portrayed as a system that is interconnected between people, land and animals. If technology serves to detach this interconnectivity, it would not be accepted. All of the participants highlighted the responsibility and role of the federal and provincial government in designing policies that would address concerns around the adoption of digital agriculture and to better improve the distribution of benefits. Three of the participants (all professors) emphasized the ethical responsibility of governments to regulate agricultural data that corporations are controlling at the expense of small farmers. They believed that the government should decommodify the food system and the food production industry by engaging more agricultural stakeholders and safeguarding the livelihood and data privacy of small farmers. This perspective is echoed by other scholars (Weersink, 2018). For digital agriculture to be considered as an equalizer, one professor stated:

Right now, big companies see digital agriculture as a money-making venture to consolidate power at the expense of the society. There is an important need for not only ethics but for serious regulations and I think this is a very important place for government to step in with a heavy hand and make sure that what happens in this wild west starts to benefit small agricultural stakeholders also. I do not trust the companies at all, and if the government steps in and starts to realize the value of this data, digital agriculture could be a great equalizer (Academia 3). 
However, as noted previously, farmers may also have concerns around government surveillance. As such, data ownership is a challenging issue that needs to be explored further in the development of ethical and responsible digital agriculture innovation.

\section{DISCUSSION}

Of all the different revolutions in agriculture, digital agriculture stands out in its method of collecting large volumes of data (i.e. Big Data), and in how it is designed to take out the extensive knowledge it takes to do farming, and "simplify" the process of decision making through digital agriculture tools (Liu and Sengers, 2021). Digital agriculture is premised on the idea that with the press of a button, evidence-based recommendations will be provided to farmers based on harvested farm data (e.g water, soil, and temperature etc). Instead of humans advising humans, artificial intelligence, modeling, and algorithm can provide this advice and "tell the truth" (Miles, 2019). Despite being identified as a "revolution", Miles (2019) argues that digital agriculture is simply a continuation of the status quo of conventional farming, but one that is structured around informatics and algorithmic principles. Although most proponents have discussed digital agriculture as a way to simplify decision making process, one academic noted that digital agriculture is not really about reducing complexity, but rather about considering "all the complexity" and learning from that through gathering "a large enough data set" (Academic 3). Yet many questions remain, namely, who manages the data and who will be served by the data?

In fact, the question of "who will this technology serve?" was raised by many of the participants in this study. Several academics and training consultants raised concerns over the cost of these technologies when so many farmers are already straddled with debt. These questions are relevant as current studies have shown that smaller and more diverse farms are not supported by current digital agriculture tools (Bronson, 2019). One private consultant identified the need for farmers to have the full set of financial information and projection to be able to make informed decisions about potential investments in the technology as the full economic risks are not clear. The issue of technological treadmill, which intensifies corporate dependency has been addressed extensively in the literature (Carolan, 2020) and was also raised by participants. As the cost of digital technologies increases yearly, farmers may undertake more debt to keep their farming production line economically viable (Rotz et al., 2019; McKinnon, 2019; McMichael, 2013). Although most of the of the participants provided neutral definitions of digital agriculture, there were clear tensions in how digital agriculture was communicated and perceived by some. For example, one academic educator equated digital agriculture with "high cost" technologically dependent agriculture that only those "with the most money can benefit from" (Academic 1). Others are similarly cautious but see digital agriculture as having the potential of being the "great equalizer" (Academic 3). There is tension in discourse because the definition of digital agriculture can seem all encompassing, covering a broad range of low cost to high-cost technologies. While many digital technologies (e.g. cellphones, online spreadsheets) have been used by farmers for a long time and are not necessarily new, there is recognition that digital agriculture is a new approach to gathering and using agricultural data, so as one academic argues, we need to "move with caution" (Academic 2).

Interestingly, there are significant differences between the perspectives of government interviewees and academic perspectives on opportunities in digital agriculture. The government staff interviewed felt that digital agriculture will attract more people to farming, especially youth, and especially those who have negative views of farming as a profession where one has to do "weeding" or "feeding" (Government 2). This excitement for digital agriculture is similar to the sentiment of the past with the idea that the new crop of farmers entering agricultural university should not need to get their hands "dirty" (Lawr, 1972). In contrast to the government staff, trainers and academics doing the work with farmers and students respond in a less enthusiastic or more neutral way. As these educators and trainers disseminate knowledge and training on agriculture and digital agriculture, the issue of the skillset needed to participate in digital agriculture naturally came up. Educators and trainers discussed using sonar technologies, to teaching regression analysis and R-based analysis for the purposes of digital agriculture. However, beyond farmers being seen as hesitant to learn (due to age etc.), educators noted that the majority of their students in post-secondary institutions studying agriculture were intimidated by digital agriculture, and in the word of one professor who teaches students how to use drones and analyze statistical data, most of his students who want to enter into farming "would rather not worry about digital agriculture" (Academic 2). As Academic 1 noted, there is a new generation of students interested in farming who are seeking a different lifestyle, who are not "hyper-capitalistic" and seek more connection to plants, land, and animals to develop wholesome food systems. A question to consider is whether digital agriculture will disconnect or better connect people with plants, land, and animals.

The issues stated above have to do with the concept of knowledge "legibility" as discussed in the literature by Liu and Sengers (2021). In terms of equity and food sovereignty, the work of Liu and Sengers (2021) in the United States on legibility highlights the harm of digital agriculture logic that is premised on both extractive data logics and colonial settler logics upon racialized and marginalized communities. Legibility "refers to systems of governance that use simplified understandings of a situation to control and direct management action upon it" (Liu and Sengers, 2021, 6). They argue that digital agriculture has introduced forms of legibility to simplify agriculture so as to make it reducible to data that can be crunched by machines and where the farmer's personal hands-on experience and knowledge are devalued or obsolete. There is also the assumption that the digital agriculture model is "homologous to the outside world" and can be parachuted anywhere without understanding the nuances of context (Liu and Sengers, 2021, 6). As an interviewee noted, those who are "good at digital agriculture" and who analyze big data 
sets are not necessarily those who will make decisions on the ground about keeping animals alive or plants alive (Academic 3). Nor do digital agriculture considerations integrate the role of migrant farm workers, peasant farmers, or other agricultural labourers that perform important functions in farming. Without addressing these underlying colonial settler logics and worldviews from a policy or regulatory standpoint, and without engaging with critical data studies, digital agriculture, just like its predecessors (the green revolution), will not help address the extreme inequalities and injustices in the food system, most of which negatively and disproportionately impact racialized communities (Sbicca, 2012).

Another aspect critical to food sovereignty is the importance of knowledge, including what types of knowledge will potentially be lost with a dependence on digital agriculture. These concerns were raised by participants due to the fact that technologies do tend to breakdown. For example, Carolan M. S. (2017) found that the Green Revolution has accelerated the loss of knowledge about crop management practices which allowed societies to grow food not only under adverse weather conditions, but also without the need of agrochemicals and expensive non-renewable resources. Similarly, digital agriculture could lead to the erosion of tacit skills that farmers gain from their farming experience due to an excessive reliance on the use of digital agriculture to make decisions over the operation of their farms. Tacit skills to be able to feel, practice and perform farming activities should be strengthened and digital agriculture should complement and support these practices instead of eliminating the need for traditional farming knowledge.

Data sovereignty is another element that ties to the broader issue of food sovereignty and equity, focusing on who decides, owns, manages, and governs the harvested data. As noted in the interviews, there is a vast difference when farmers are the sole proprietor of their data, compared to when it is managed and controlled by larger corporations, including when data is managed by government. A government staff member noted that smaller farmers may withhold taxes due to not making sufficient money and therefore may feel concerned about government surveillance should they participate in digital agriculture. This view seems to identify smaller farmers as a group that cannot be trusted and have unsubstantiated fear, but does not recognize the fact that data-driven farming has been used by large corporations to perform acts of surveillance ranging from data trading and data grabs of previously private data, to copyrighting data to prevent farmers from fixing their equipment (Ravis and Notkin, 2020). It is also important to unpack the idea that by simply making digital agriculture open access, that it will therefore be equal (Kloppenburg, 2014; Carbonell, 2016), particularly when considering the power of the intellectual property regimes currently being established by corporations to control the data (Carolan, 2020).

With regard to social equity, all of the participants interviewed highlighted the responsibility and role of the federal and provincial governments in designing policies that would better improve the distribution of benefits from the technology and addressing the barriers that have been identified in this study. However, this study found that there is currently a lack of critical data studies, ethical, and critical social scientific awareness in digital agriculture training/education both in the government and in academia. In the U.S, there have been calls to ensure the integration of social sciences and humanities in science research and development (Viseu, 2015). Educators should ensure that digital agriculture is developed and taught with considerations of social justice and ethics (Ferreira and Vardi, 2021), and those from the natural and technical science or industry sector working in this field, should consider hiring or integrating social scientists as part of their team (Viseu, 2015). Responsible innovation should also ensure the inclusion of farmers in designing and developing tools that would help support their work. However, inclusion of stakeholders alone is not enough. As van Mierlo et al., (2020) identified, key to responsible research and innovation is inclusion in the development and innovation processes that allow for values and ideas that challenge the dominant assumptions, values and interests of proponents. As we found in the study, the fact that several participants noted that regenerative organic agriculture acts as a barrier to digital agriculture adoption means that the field of digital agriculture should be more "opened up" to including these values (van Mierlo et al., 2020, 379).

\section{CONCLUSION}

The paper started with three main objectives: 1) To explore educators'/trainers' perspectives and approaches to the benefits and risks of digital agricultural technologies in their education, communication, and training; 2) To assess whether digital agriculture training and or pedagogy includes/consider outcomes such as social equity and food sovereignty; and 3) To identify appropriate policies to promote an ethical and responsible approach to digital agriculture in education and training. As to the benefits and risks, this paper concludes that the three categories of educators (academics, government staff, and private agricultural consultants) have differing, at times diametrically opposed communications around the benefits and risks of digital agriculture. This is particularly the case with academics or trainers who have a deeper understanding of social equity issues, as opposed to those who approach digital agriculture from a purely technical, environmental or economic perspective. Our study found that while government officials are highly supportive and have more optimistic discourse with the digitization of British Columbia's agricultural sector, there were more concerns or skepticism raised about digital agriculture with the academics and trainers interviewed.

As for objective two on social equity and food sovereignty, the fact that racialized farm labourers and Indigenous communities were not mentioned at all in the context of farming work identified a major gap, particularly when they are currently at a disadvantage in terms of capital, land, and resources. This ties back to Liu and Sengers (2021) concerns around the settler colonial logics and the erasure of peoples and knowledges through current digital agriculture regimes. It is important to note that land sovereignty, knowledge sovereignty, data sovereignty, and Indigenous food sovereignty are all 
interconnected issues (Fraser, 2019). These interconnected issues have not been sufficiently addressed.

It was also clear from the findings that current digital agriculture training and education lacked deep insights around social equity and food sovereignty (with a few exceptions as noted by some of the participants). The focus on equity was shallow and centred around the question of access to the tools, but not a critical engagement on the purpose/intent of the digital agriculture itself and what problem is it really trying to solve. As such, emphasis on increasing internet infrastructure to encourage participation in digital agriculture or encouraging open-source digital agriculture may gloss over deeper questions, namely, whether digital agriculture and a focus on increasing food production can help address some of the root causes around inequities in the food system. Otherwise, we, as Kloppenburg argues (as it pertains to open source), will simply be "re-purposing the master's tools" rather than making truly systemic changes $(2014,1,225)$. As a technological innovation, digital agriculture will change the dynamics and transform the assemblages, and governance of agricultural operations in British Columbia and beyond. As such, any form of digitization must be practiced and taught in a way that promotes responsible research and innovation (Rose and Chilvers, 2018). Considering that this research is still emerging, and the educators are still small in number, there is time to ensure ethical education in this domain and the ethical development of technologies.

To conclude, this study identified numerous gaps and misunderstandings with respect to the definition of digital agriculture, as well as tensions around the role of digital agriculture and its future. To promote responsible and ethical innovation, the introduction of digital agriculture as a scientific pursuit to promote sustainability and economic benefits in agriculture should not be done without sufficient social considerations as well as social scientific engagement. Without social considerations, the drive for sustainability is incomplete and there may be gaps in knowledge for the next generation of practitioners as well as unintended consequences. It is therefore important for academic institutions and trainers to ensure deep engagement with farmers in the development and testing of agricultural

\section{REFERENCES}

AgriService BC (2019). Fast Stats 2018- British Columbia's Agriculture, Food and Seafood Sector. Retrieved from https://www2.gov.bc.ca/assets/gov/farmingnatural-resources-and-industry/agriculture-and-seafood/statistics/industryand-sector-profiles/fast-stats/fast_stats_2018.pdf.

Balafoutis, A., Beck, B., Fountas, S., Vangeyte, J., Wal, T. V. D, Soto, I., et al. (2020). Precision Agriculture Technologies Positively Contributing to GHG Emissions Mitigation, Farm Productivity and Economics Sustainability 9 (8), 1339. doi:10.3390/su9081339

Basso, B., and Antle, J. (2020). Digital Agriculture to Design Sustainable Agricultural Systems. Nat. Sustain. 3, 254-256. doi:10.1038/s41893-0200510-0

B.C. Food Security Task Force (2020). The Future of B.C.'s Food System (Findings and Recommendations). Retrieved from: https://engage.gov.bc.ca/app/upl oads/sites/121/2020/01/FSTF-Report-2020-The-Future-of-Food.pdf. innovations to ensure that these technologies will result in positive social benefits to farmers (particularly small farmers, and new farmers), Indigenous peoples/Host Nation(s), and also deep engagement with critical social scientists. Whether digital or not, an educational/training sector that recognizes the nuances of digital agriculture (the good, the bad, and the ugly) and challenges the unequal structure that is at the root of food injustice, is what is needed to ensure the development of an equitable and sustainable food system.

\section{DATA AVAILABILITY STATEMENT}

The datasets presented in this article are not readily available because as required by ethics, we will delete all data including transcripts 3 years after the completion of this study. Requests to access the datasets should be directed to tammara_soma@sfu.ca.

\section{ETHICS STATEMENT}

The studies involving human participants were reviewed and approved by the Simon Fraser University Research Ethics Board. The participants provided their written informed consent to participate in this study.

\section{AUTHOR CONTRIBUTIONS}

The authors confirm contribution to the paper as follows: study conception and design: TS.; data collection: BN. Author; analysis and interpretation of results: $\mathrm{BN}$ and TS.; draft manuscript preparation: BN and TS. All authors reviewed the results and approved the final version of the manuscript.

\section{FUNDING}

This study was funded by the Social Sciences and Humanities Research Council Insight Grant 435-2019-0155.

Bolfe, É. L., Jorge, L. A. D. C., Sanches, I. D. A., Luchiari Júnior, A., da Costa, C. C., Victoria, D. D. C., et al. (2020). Precision and Digital Agriculture: Adoption of Technologies and Perception of Brazilian Farmers. Agriculture 10 (12), 653. doi:10.3390/agriculture10120653

Bronson, K., and Knezevic, I. (2019). The Digital divide and How it Matters for Canadian Food System Equity. Can. J. Commun. 44 (2), 63-68. doi:10.22230/ cjc. $2019 v 44 n 2 a 3489$

Bronson, K. (2019). Looking through a Responsible Innovation Lens at Uneven Engagements with Digital Farming. NJAS - Wageningen J. Life Sci. 90-91, 100294. doi:10.1016/j.njas.2019.03.001

Bronson, K., Rotz, S., and D’Alessandro, A. (2021). “The Human Impact of Data Bias and the Digital Agricultural Revolution," in Handbook on the Human Impact of Agriculture. Editor H. S. JamesJr (Northampton: Edward Elgar Publishing), 119-137. doi:10.4337/9781839101748.00017

Brunner, D. (2019). Transforming Farming through Innovation. Retrieved from https://albertainnovate s.ca/impact/newsroom/transforming-farming-throughinnovation/. 
Carbonell, I. M. (2016). The Ethics of Big Data in Big Agriculture. Internet Pol. Rev. 5 (1), 1-13. doi:10.14763/2016.1.405

Carolan, M. (2018). 'Smart' Farming Techniques as Political Ontology: Access, Sovereignty and the Performance of Neoliberal and Not-So-Neoliberal Worlds. Sociologia Ruralis 58 (4), 745-764. doi:10.1111/soru.12202

Carolan, M. (2017b). Agro-Digital Governance and Life Itself: Food Politics at the Intersection of Code and Affect. Sociologia Ruralis 57, 816-835. doi:10.1111/ soru. 12153

Carolan, M. (2020). Automated Agrifood Futures: Robotics, Labor and the Distributive Politics of Digital Agriculture. J. Peasant Stud. 47 (1), 184-207. doi:10.1080/03066150.2019.1584189

Carolan, M. S. (2017a). No One Eats Alone: Food as a Social enterprise. Washington, DC: Island Press.

Cheek, J. (2004). At the Margins? Discourse Analysis and Qualitative Research. Qual. Health Res. 14 (8), 1140-1150. doi:10.1177/1049732304266820

Clapp, J., and Ruder, S.-L. (2020). Precision Technologies for Agriculture: Digital Farming, Gene-Edited Crops, and the Politics of Sustainability. Glob. Environ. Polit. 20 (3), 49-69. doi:10.1162/glep_a_00566

Custers, B. (2016). Click Here to Consent Forever: Expiry Dates for Informed Consent. Big Data Video Edition 3 (1), 1-6. doi:10.1177/2053951715624935

Duncan, E., Abdulai, A. R., and Fraser, E. D., Jr (2021). "Modernizing Agriculture through Digital Technologies: Prospects and Challenges," in Handbook on the Human Impact of Agriculture. Editors H. S. James (Cheltenham: Edward Elgar Publishing), 138-162.

Edwards, J. P., Kuhn-Sherlock, B., Dela Rue, B. T., and Eastwood, C. R. (2020). Short Communication: Technologies and Milking Practices that Reduce Hours of Work and Increase Flexibility through Milking Efficiency in Pasture-Based Dairy Farm Systems. J. Dairy Sci. 103 (8), 7172-7179. doi:10.3168/jds.201917941

Fairclough, N. (2003). Analyzing Discourse: Textual Analysis for Social Research. London: Routledge.

Ferreira, R., and Vardi, M. Y. (2021). "Deep Tech Ethics: An Approach to Teaching Social Justice in Computer Science," in SIGCSE 2021 - Proceedings of the 52nd ACM Technical Symposium on Computer Science Education (New York, NY: Association for Computing Machinery), 1041-1047. doi:10.1145/ 3408877.3432449

Firbank, L. G., Attwood, S., Eory, V., Gadanakis, Y., Lynch, J. M., Sonnino, R., et al. (2018). Grand Challenges in Sustainable Intensification and Ecosystem Services. Front. Sustain. Food Syst. 2. doi:10.3389/fsufs.2018.00007

Fleming, A., and Vanclay, F. (2009). Using Discourse Analysis to Improve Extension Practice. Extension Farming Syst. J. 5 (1), 1-9.

Francis, C., Lieblein, G., Gliessman, S., Breland, T. A., Creamer, N., Harwood, R., et al. (2003). Agroecology: The Ecology of Food Systems. J. Sust. Agric. 22 (3), 99-118. doi:10.1300/J064v22n03 10

Fraser, A. (2019). Land Grab/data Grab: Precision Agriculture and its New Horizons. J. Peasant Stud. 46 (5), 893-912. doi:10.1080/ 03066150.2017.1415887

Garnett, T., and Godfray, C. (2012). Sustainable Intensification in Agriculture. Navigating a Course through Competing Food System Priorities. Oxford, United Kingdom: Food Climate Research Network and the Oxford Martin.

Gill, D. S. (1996). Reframing Agricultural Extension Education Services in Industrially Developed Countries: A Canadian Perspective. Retrieved from https://era.library.ualberta.ca/items/ad4ed035-621b-44eb-94b8-7ac419e23e8c.

Government of British Columbia (2020). Food Security Task Force-Results. Retrieved from https://engage.gov. bc.ca/govtogetherbc/impact/food-securitytask-force-results/.

Government of Canada (2018). Government of Canada to Invest in National Initiatives for Automation and Digital Technologies in the Agriculture and Agri-Food Sector. Retrieved from https://www.canada.ca/en/ innovation-science-economic-development/news/2018/12/government-ofcanada-to-invest-in-national-initiatives-for-automation-and-digital-technologiesin-the-agriculture-and-agri-food-sector.html.

Government of Canada (2020). Overview of the Canadian Agriculture and Agri-Food Sector 2018. Retrieved from: https://agriculture.canada.ca/en/ canadas-agriculture-sectors/sector-overviews-data-and-reports/overviewcanadian-agriculture-and-agri-food-sector-2018.

Hansen, E., Robert, N., Bomford, M., Harbut, R., and Mullinix, K. (2020). Response to the Findings and Recommendations of the B.C. Food Security Task Force.
Richmond, British Columbia: Institute for Sustainable Food Systems, Kwantlen Polytechnic University. Retrieved from: https://www.kpu.ca/sites/default/files/ ISFS\%20Response_layoutFI NAL_0.pdf.

Hilimire, K., Gillon, S., McLaughlin, B. C., Dowd-Uribe, B., and Monsen, K. L. (2014). Food for Thought: Developing Curricula for Sustainable Food Systems Education Programs. Agroecology Sust. Food Syst. 38 (6), 722-743. doi:10.1080/ 21683565.2014.881456

Jordan, N., Grossman, J., Lawrence, P., Harmon, A., Dyer, W., Maxwell, B., et al. (2014). New Curricula for Undergraduate Food-Systems Education: A Sustainable Agriculture Education Perspective. NACTA J. 58 (4), 302-310.

Klerkx, L., Jakku, E., and Labarthe, P. (2019). A Review of Social Science on Digital Agriculture, Smart Farming and Agriculture 4.0: New Contributions and a Future Research Agenda. NJAS - Wageningen J. Life Sci. 90-91, 100315. doi:10.1016/j.njas.2019.100315

Kloppenburg, J. (2014). Re-purposing the Master's Tools: the Open Source Seed Initiative and the Struggle for Seed Sovereignty. J. Peasant Stud. 41 (6), 1225-1246. doi:10.1080/03066150.2013.875897

Kooistra, L., Van der Wal, T., and Poppe, K. (2015). "The Role of New Data Sources in Greening Growth - the Case of Drones," in Conference: Green Growth and Sustainable Development Forum 2015-Enabling the Next Industrial Revolution: Systems Innovation for green Growth (Paris, France. OECD Organisation for Economic Co-operation and Development). Retrieved from: https://www. researchgate.net/publication/286449965_The_role_of_new_data_sources_in_ Greening_Growth_-_the_case_of_Drones.

Lawr, D. A. (1972). Agricultural Education in Nineteenth-Century Ontario: An Idea in Search of an Institution. Hist. Edu. Q. 12 (3), 334-357. doi:10.2307/367517

Levkoe, C. Z., Knezevic, I., Appavoo, D., Moraes, A., and Scott, S. (2020). Serving up Food Studies Online: Teaching about "Food from Somewhere" from Nowhere. Food Cult. Soc. 23 (3), 434-453. doi:10.1080/15528014.2020.1754041

Liu, J., Mooney, H., Hull, V., Davis, S. J., Gaskell, J., Hertel, T., et al. (2015). Systems Integration for Global Sustainability. Science 347 (6225), 1258832. doi:10.1126/ science. 1258832

Liu, J., and Sengers, P. (2021). Legibility and the Legacy of Racialized Dispossession in Digital Agriculture. Proc. ACM Hum.-Comput. Interact. 5 (CSCW2), 1-21. doi: $10.1145 / 3479867$

Lowder, S. K., Skoet, J., and Raney, T. (2016). The Number, Size, and Distribution of Farms, Smallholder Farms, and Family Farms Worldwide. World Dev. 87, 16-29. doi:10.1016/j.worlddev.2015.10.041

Mars, M., and Ball, A. (2016). Ways of Knowing, Sharing, and Translating Agricultural Knowledge and Perspectives: Alternative Epistemologies across Non-formal and Informal Settings. Jae 57 (1), 56-72. doi:10.5032/ jae. 2016.01056

McKinnon, C. (2019). Sleepwalking into Lock-In? Avoiding Wrongs to Future People in the Governance of Solar Radiation Management Research. Environ. Polit. 28 (3), 441-459. doi:10.1080/09644016.2018.1450344

McMichael, P. (2013). Value-chain Agriculture and Debt Relations: Contradictory Outcomes. Third World Q. 34 (4), 671-690. doi:10.1080/01436597.2013.786290

Mehrabi, Z., McDowell, M. J., Ricciardi, V., Levers, C., Martinez, J. D., Mehrabi, N., et al. (2021). The Global divide in Data-Driven Farming. Nat. Sustain. 4, 154-160. doi:10.1038/s41893-020-00631-0

Migliorini, P., Wezel, A., Veromann, E., Strassner, C., Średnicka-Tober, D., Kahl, J., et al. (2020). Students' Knowledge and Expectations about Sustainable Food Systems in Higher Education. Ijshe 21 (6), 1087-1110. doi:10.1108/IJSHE-122019-0356

Miles, C. (2019). The Combine Will Tell the Truth: On Precision Agriculture and Algorithmic Rationality. Big Data Soc. 6 (1), 2053951719849444. doi:10.1177/ 2053951719849444

Newell, P., and Taylor, O. (2018). Contested Landscapes: the Global Political Economy of Climate-Smart Agriculture. J. Peasant Stud. 45 (1), 108-129. doi:10.1080/03066150.2017.1324426

Ozdogan, B., Gacar, A., and Aktas, H. (2017). Digital Agriculture Practices in the Context of Agriculture 4.0. Pressacademia 4 (2), 184-191. doi:10.17261/ pressacademia.2017.448

Paltridge, B. (2021). Discourse Analysis: An Introduction. London: Bloomsbury Academic.

Panday, D. (2017). Digital Farming: Fostering Young People in Agricultural Landscape. Rome, Italy: World Farmers' Organization Technical Report number, 66 
Pant, L. P., and Hambly Odame, H. (2017). Broadband for a Sustainable Digital Future of Rural Communities: A Reflexive Interactive Assessment. J. Rural Stud. 54, 435-450. doi:10.1016/j.jrurstud.2016.09.003

Ravis, T., and Notkin, B. (2020). Urban Bites and Agrarian Bytes: Digital Agriculture and Extended Urbanization. Berkeley Plann. J. 31, 1. doi: $10.5070 / \mathrm{bp} 331044067$

Rose, D. C., and Chilvers, J. (2018). Agriculture 4.0: Broadening Responsible Innovation in an Era of Smart Farming. Front. Sustain. Food Syst. 2, 1. doi:10.3389/fsufs.2018.00087

Rotz, S., Gravely, E., Mosby, I., Duncan, E., Finnis, E., Horgan, M., et al. (2019). Automated Pastures and the Digital divide: How Agricultural Technologies Are Shaping Labour and Rural Communities. J. Rural Stud. 68, 112-122. doi:10.1016/j.jrurstud.2019.01.023

Saunders, C., Driver, T., Mowat, A., Kaye-Blake, W., Payn, T., Bayne, K., et al. (2016). Driving Better Programme Investment and Accelerating Challenge Impact through a Prioritisation Matrix of International and National Perspectives. Retrieved from https://ourlandandwater.nz/wp-content/ uploads/2019/03/Matrix_report-B-2016-09-30-002-FINAL-OLW.pdf.

Sbicca, J. (2012). Growing Food justice by Planting an Anti-oppression Foundation: Opportunities and Obstacles for a Budding Social Movement. Agric. Hum. Values 29 (4), 455-466. doi:10.1007/s10460-012-9363-0

Schmaltz, R. (2019). Canada AgriFood Tech Market Map: 166 Startups Growing Canada's Agricultural Sector. Retrieved from https://agfundernews.com/ canada-agrifood-tech-market-map-166-startups-grow-canadas-agriculturalsector.html.

Shen, S., Basist, A., and Howard, A. (2010). Structure of a Digital Agriculture System and Agricultural Risks Due to Climate Changes. Agric. Agric. Sci. Proced. 1, 42-51. doi:10.1016/j.aaspro.2010.09.006

Shepherd, M., Turner, J. A., Small, B., and Wheeler, D. (2020). Priorities for Science to Overcome Hurdles Thwarting the Full Promise of the 'digital Agriculture' Revolution. J. Sci. Food Agric. 100 (14), 5083-5092. doi:10.1002/jsfa.9346

Shulman, L. S. (2005). Signature Pedagogies in the Professions. Daedalus 134 (3), 52-59. doi:10.1162/0011526054622015

Sinclair, J. (2004). “Trust the Text,” in Trust the Text. 1st ed. (London: Routledge). doi:10.4324/9780203594070

Skinner, K., Hanning, R. M., Desjardins, E., and Tsuji, L. J. (2013). Giving Voice to Food Insecurity in a Remote Indigenous Community in Subarctic Ontario, Canada: Traditional Ways, Ways to Cope, Ways Forward. BMC Public Health 13 (1), 427-440. doi:10.1186/1471-2458-13-427

Smith, B. E. (2012). A Work in Progress - the British Columbia farmland Preservation Program. Retrieved from https://www.alc.gov.bc.ca/alc/content/ library/archived-publications/alr-history.

Statistics Canada (2021). Farms Reporting Technologies Used on the Operation in the Year Prior to the Census. Retrieved from https://www150.statcan. gc.ca/t1/tbl1/en/tv.action?pid=3210044601 andpickMembers\%5B0\%5D=1. 2010.

Sumner, J. (2015). Reading the World: Food Literacy and the Potential for Food System Transformation. Stud. Edu. Adults 47 (2), 128-141. doi:10.1080/ 02660830.2015 .11661680

Tey, Y. S., and Brindal, M. (2012). Factors Influencing the Adoption of Precision Agricultural Technologies: a Review for Policy Implications. Precision Agric. 13 (6), 713-730. doi:10.1007/s11119-012-9273-6
Valley, W., Wittman, H., Jordan, N., Ahmed, S., and Galt, R. (2018). An Emerging Signature Pedagogy for Sustainable Food Systems Education. Renew. Agric. Food Syst. 33 (5), 467-480. doi:10.1017/S1742170517000199

Van der Burg, S., Bogaardt, M.-J., and Wolfert, S. (2019). Ethics of Smart Farming: Current Questions and Directions for Responsible Innovation towards the Future. NJAS - Wageningen J. Life Sci. 90-91, 100289. doi:10.1016/ j.njas.2019.01.001

van Mierlo, B., Beers, P. J., and Hoes, A. S. (2020). Inclusion in Responsible Innovation: Revisiting the Desirability of Opening Up. J. Responsible Innov. 7(3), 361-383. doi:10.1080/23299460.2020.1780409

Viseu, A. (2015). Caring for Nanotechnology? Being an Integrated Social Scientist. Soc. Stud. Sci. 45 (5), 642-664. doi:10.1177/0306312715598666

Weersink, A. (2018). The Growing Heterogeneity in the Farm Sector and its Implications*. Can. J. Agric. Economics/Revue canadienne d'agroeconomie 66 (1), 27-41. doi:10.1111/cjag.12163

Weiler, A. M., McLaughlin, J., and Cole, D. C. (2017). Food Security at Whose Expense? A Critique of the Canadian Temporary Farm Labour Migration Regime and Proposals for Change. Int. Migr 55 (4), 48-63. doi:10.1111/ imig. 12342

White, B. (2012). Agriculture and the Generation Problem: Rural Youth, Employment and the Future of Farming. IDS Bulletin 43 (6), 9-19. doi:10.1111/j.1759-5436.2012.00375.x

Wield, D., Chataway, J., and Bolo, M. (2010). Issues in the Political Economy of Agricultural Biotechnology. J. Agrarian Change 10 (3), 342-366. doi:10.1111/ j.1471-0366.2010.00274.x

Wiseman, L., Sanderson, J., Zhang, A., and Jakku, E. (2019). Farmers and Their Data: An Examination of Farmers' Reluctance to Share Their Data through the Lens of the Laws Impacting Smart Farming. NJAS - Wageningen J. Life Sci. 9091, 100301. doi:10.1016/j.njas.2019.04.007

Wittman, H. (2011). Food Sovereignty: a New Rights Framework for Food and Nature? Environ. Soc. 2 (1), 87-105. doi:10.3167/ares.2011.020106

Yamada, H., Shimamoto, D., and Wakano, A. (2015). Importance of Informal Training for the Spread of Agricultural Technologies: Farmers as In-residence Extension Workers and Their Motivation for Sustainable Development. Sust. Dev. 23 (2), 124-134. doi:10.1002/sd.1580

Conflict of Interest: The authors declare that the research was conducted in the absence of any commercial or financial relationships that could be construed as a potential conflict of interest.

Publisher's Note: All claims expressed in this article are solely those of the authors and do not necessarily represent those of their affiliated organizations, or those of the publisher, the editors and the reviewers. Any product that may be evaluated in this article, or claim that may be made by its manufacturer, is not guaranteed or endorsed by the publisher.

Copyright (c) 2021 Soma and Nuckchady. This is an open-access article distributed under the terms of the Creative Commons Attribution License (CC BY). The use, distribution or reproduction in other forums is permitted, provided the original author(s) and the copyright owner(s) are credited and that the original publication in this journal is cited, in accordance with accepted academic practice. No use, distribution or reproduction is permitted which does not comply with these terms. 